\section{One Hundred Years of Physics in Finance}

It has a longer history than you might expect. 'It is not even very modern,' says Sorin Solomon of econophysics. Solomon is a theoretical physicist at the Hebrew University, Jerusalem, but knows a thing or two about stock markets. 'Exactly onehundred years ago in 1897 a French-born engineer, Pareto, wrote a book about economics in which the declared objective was to transform economics into something like a physical science. This was the first time someone took seriously the successes of physics and tried to carry them over into economics,' Solomon explains.

Solomon is drawn to stock markets because like many econophysicists he has found you can apply the statistical mechanics of critical systems: 'If you have a complex system, most of the time it is because there are very many elements interacting by rather simple laws. And the complexity comes just because there are so many - emergent properties arise.'

In econophysics, you assume that a complex price history arises because there are very many traders interacting by rather simple rules. According to econophysicists, the behaviour of prices emerges from the interactions between traders, like the pressure of a gas emerging from the interactions of molecules.

Pareto, one hundred years ago, foresaw that physics could be useful in trying to understand the stock market. But, lacking a computer, he was restricted by the approximations that limited the work of all physicists of the time.

'Then in 1900 a thesis by Bachelier was essentially the statistical mechanics of stock markets.' Solomon continues. 'At the same time there was another French professor, Paul Levy. He was considered a little bit of a crackpot, but eventually got a professorship. He made quite good progress in mathematical distributions, which turn out to be relevant for the stock market.'

Fluctuations in stock prices are not well described by a simple random walk, which would lead to a Gaussian distribution if you plotted a graph of deviations from the norm. In physical systems fluctuations are usually Gaussian. But in economics, things are different.

'In economics, and in these distributions which Levy discovered, the fluctuations can be arbitrarily large,' Solomon explains. 'And this is very hot stuff; each time you see a big fluctuation in the stock market it is this difference between the Gaussian fluctuations and the Levy fluctuations.'

'The next person to try and bring the hard sciences into the soft was $\mathrm{Zipf}$ in the 20 s and 30 . He was a professor at Princeton. He got very excited about populations of towns which are distributed according to power laws,' Solomon says.

Power laws are different from exponential laws which, for instance, describe the distribution of energies in a gas. 'There is a simple way to express the difference between typical physical systems and the economic system which is the origin of the difference between power laws and exponential laws,' explains Solomon. 'When molecules change their energy, they can loose or gain a quantum of energy. When a person gains or looses on the stock market, they gain or loose a fraction of their investment.'

(Recently, econophysicists have found that distributions of variations in market prices fit a power law truncated by an exponential at short time scales, less than one day, and look more like a Gaussian at monthly time scales and longer.)

In the 1960 s, power laws turned into fractals, which in a sense are geometrical expressions of power distributions. 'Without Mandelbrot much of these things would have been forgotten,' says Solomon. But the field really opened up to physicists with Kenneth Wilson's work.

Kenneth Wilson, who the Nobel prize for physics in 1982, said: 'For a very wide range of microscopic interactions, if they share the same general symmetry properties they will eventually have macroscopic interactions which are identical,' explains Solomon. 'This gave us the courage to go to systems of economics. You can not enter in the mind of each of the persons who deals on the stock market and understand what he does there. But these very powerful techniques in statistical mechanics and field theory guarantee to you that in certain conditions the macroscopic properties are independent of some of the details of the microscopic interactions.'

These days, there are a few teams of physicists around the world that have turned their mathematical expertise to matters of finance.

One of the main tools is the computer model: a simulation of the transactions made by a large group of traders. In Zhang's model (see page 4) traders can learn from each other, and trade only one stock by assessing past prices. Other model builders select slightly different aspects of trading.

Solomon himself built a model in 1994 in which traders have different memory spans, and so assess price changes over different periods.

Didier Sornette, at Nice University, constructed last year a hierarchical model of traders who imitate their superiors.

Professor Sornette, however, has done more than just build computer models. According to Zhang: 'Didier Sornette is involved in making financial tools: how to make profit. He is successful in marketing his methods. He may never publish a complete history of his theories because there is real money involved in his trading strategies.'

Sornette is one example of a physicist prepared to put his money where his theories are: with a colleague he bet on the market crash of last October, and made 500 per cent profit. This, naturally, raises the question: will econophysicists soon be leaving their physics departments heading for the trading floor?

It's known to be a possibility; and it's most likely, according to many econophysicists, to involve betting on the shortterm volatility of a market, by trading options, for example.

However, Marcel Ausloos, Université de Liege, Belgium, who made an appearance on Belgium television last year because he also predicted last October's crash, thinks that physicists like himself are not likely to make much money - the predictions are short term so riches will be earned only by wealthy and powerful brokers.

But anyhow, econophysics is not for those who like a quiet life. Different models are always hotly debated. And often hotly denounced by economists.

Dietrich Stauffer, at Köln University, is currently writing a review called NonTraditional Applications of Computational Statistical Physics, which he hopes to publish next year; it ranges from bird song to immunology, and one chapter covers financial models. Zhang: 'One sees in his review that all the approaches are disparate. This science is not mature yet. Maybe this is a good thing: you don't want to unify, you don't want to make everyone agree with one authority.'

At the moment econophysicists around the world are trading ideas, speculating on the best models and the best strategies for understanding. All are hoping to get rich with knowledge. (TC)

Part 2 next issue:

An article by $Y i$-Cheng Zhang 